restored by raising it to a white heat, and then placing it to the explanation of the hardening and tempering of steel; as are possible at a lecture, some of the properties of the uuder the rapid action of a steam hammer. Chernoff also and to ascertain by experiment whether absorption and ex- metal. I will begin by giving you a short summary of its which be treated in the above manner, and restored to its proper condition. Osborn states that steel bas a remarkable :
property of remaining in a pasty condition through a con.
siderable range of temperature below its melting point; and siderable range of temperature below its melting point; and
that bar-iron acquires a largely crystalline structure when exposed for a long time to heat considerably below fusion.
Professor Gore, in 1869, and subsequenty Professor Bar. Professor Gore, in 1869, and subsequentfy Professor Bar-
rett, in 1873,drew attention to certain anomalies that occurred
in the expansion and contraction of iron wire; and in $18 \tau 7$ in the expansion and contraction of iron wire; and in $18 \pi 7$ the same subject, which appear to confirm Chernoff's theory
in a remarkable manner. In cooling a strained iron wire from redness, it was found that the contraction due to cool ing was, at a certain point, and for a limited period, changed
into an action of elongation. In good iron wire this irreguinto an action of elongation. In good iron wire this irregu-
larity could not be detected, but in hard wire and steel it
was very apparent. The wire has to be raised to a very bigh was very apparent. The wire has to be raised to a very high
temperature before the temporary elongation during cooling,
can be seen; and it does not take place if the wire is heated can be seen; and it does not take place if the wire is heated sions: (1) That in steel, and in iron containing free carbon, sions: (1) That in steel, and in iron containing free carbon,
there is a contraction, or shortening, which is excited by
heat, and which proceeds simultaneously with the dynamical expansion, and masks its true amount. This is divisible into
high and low temperature contraction. (2) That similarly high and low temperature contraction. (2) That similarly there is a cooling expansion, or crystallization, which comes
in during the dynamical contraction, and masks its true amount. (3) That these effects, due to crystallization, and decrystallization, are the causes of the so-called "kicks," or
temporary contractions and expansions, which occur during
the beating and cooling respectively of the steel. (4) That the beating and cooling respectively of the steel. (4) That due to decrystallization and crystallization, which occur durchanges, and are proportionate to their extent. (5) That changes, and are proportionate to their extent. (5) That
protracted annealing, $i . e$., extremely slow cooling, brings
about molecular separation of the carbon and iron about molecular separation of the carbon and iron. Steel in reached, producing the effects of contraction, which are
seen at the ends of the heating, and which are due to the condensation produced by the recombination of the carbon
and iron. Steel in this state is less susceptible to cooling expansion (or crystallization), and, therefore, to low temperature contraction on subsequent beativg. It would seem that
the "kicks" observed by Professor Norris probably occur
somewhere in the region of Chernoff's temperatures, $a$ and $b$, where a change in the molecular structure of steel appears
to take place, according to his theory. At any rate it is to take place, according to his theory. At any rate it is
plain that molecular changes of some kind do occur, and manifest themselves by altering the bulk of the metal. the presence of hydrogen, nitrogen, and carbonic oxide in the recent meeting of the American Association for the Advancement of Science, at Saratoga, has extended the observations
of Döbereiner, St. Clair-Deville, Troost, Faraday, and Graham; and bas not only applied the facts ascertained to explain the destruction of refractory metals, euch as platinum and iridium, under long-continued high temperatures, but
bas discovered the means of overcoming those defects, which
have proved a serious hindrance to the extension of electric have proved a serious hindrance to the extension of electric
lighting. Edison noticed that the effect of incandescence on wires was to produce, all over their surface, innumerable
fine cracks. When the incandescence was maintained for fne cracks. When the incandescence was maintained for
twenty minutes, these ,issures became so enlarged as to be twenty minutes, these, fissures became so enlarged as to be
visible to the naked eye; and, when still further continued
for several hours, the cracks united and the wires fell to for several hours, the cracks united and the wires fell to
clusion that the cracking of the surface of the metal is due entirely to the occluded gases imprisoned within its pores which become expunded, and are driven out under the ac-
tion of beat. By beating spirals of platinum wire gradually, by means of a transmitted electric current of periodically increasing strength, and within an exhausted chamber, the ually withdrawn; and by allowing the metal, in the interval
between each increase of temperature, to cool down in vacuo, nating with a closing up and welding logether again of the had enabled the gases to escape. By continuing this simple operation, it has been found possible to change completely
the physical character of metals, increasing their hardness
and density to an extraordinary degree and raising their and density to an extraordinary degree, and raising their
points of fusion so high that they are perfectly unaffected at even volatilized. A spiral or ordinary platinum at a white beat softens and loses its elastic and rigid character; but platinum, after having been treated in the manner above
described, becomes as rigid as steel, and as bomogeneous a glass, and retains these properties when glowing under the
most intense incandescence. The metal so transformed cannot be annealed by any known process.
It appears to the committee that the expulsion of the gasescontained in the body of the metals may have the effect thereby the force of their cohesion, and consequently resisting more strongly any rearrangement that would be necesof gases in the pores of metals is an attribute of their normal
states; and that the expulsion of the gases increases hardstates; and that the expulsion of the gases increases hard-
ness and necessarily raises the melting point on account of
the stronger cohesion of the atoms. sudden contraction in hardening steel has the effect of expelling occluded gases; that subsequent tempering, by rais
ing the temperature, has the effect of permitting a fresh absorption; and that the iridescent colors which accompany
tempering are due to the change of surface caused by the tempering are due to the change of surface caused by the
infiltration of gases? Another view is that the mere beating of steel to the proper temperature for hardening is sufficient
to expel a portion of the gases, which are kept out by sudden cooling, and are slowly re-absorbed in tempering.
Grabam states that platinum at a low red heat will absorb four
times its volume of hydrogen, and that palladium condenses times its volume of hydrogen, and that palladium condenses below that of boiling water. Hiay not steel, therefore,
possess analogous properties with respect to some of the possess analogous properties with respect to some of the
gases constituting the air? May it not absorb these more
freely as the temperature of tempering rises, and so gradually
become restored to its original softness?

VI.-DIRECTIONS IN WHICH FURTHER INVEGTIGATION

APPEAR TO BE NEEDED.
(1) To investigate whether Edison's theory can be applied

whether any chemical difference exists between the oute hardening was of homogeneous structure. (3) To ascertain
whether there is any connection between Chernoff's theory nd Norris' observations on the contraction and expansion
wires. Signed on behalf of the committee, 5th Nov. wires. Signed on behalf of the committe
879, W. ANDERson, Chairman and Reporter.

List of Works Consulted.-Percy,

Metallurgy of Iron and Steel;" Chernoff, " Remarks on the Manufacture of Steel
and the Mode of Working it," 1868; Barba, "Etude sur
'emploi de l'acier dans les constructions,"1874; Camus, "L'art de tremper les fers et les aciers," 1846; Osborn, "Metallurgy of Iron and Steel," 1869; Jullien, “Thérorie
de la Trempe," 1865; Jullien, "Résume de mes recherches
sur l'aciération," 1868; Caron, "Recherches sur la comur l'aciération," 1868; Caron, " "Recherches sur la com-
position chimique des aciers." (Mémoires des savants rangers, publiés par l'Académie Royale de Belgique,
1865); Gruner, "Traité de Métallurgie." article viii., 1878 rench Navy, 1879; Gore, "On a Momentary Molecular Change in Iron Wire" (Proceedings of the Royal Society,
No. 108, 1869); Norris, "On Certain Molecular Changes which Occur in Iron and Steel During the Separate Acts of Heating and Cooling" (Proceedings of the Royal
Society, No. 180, 1877); Baumbauer, "On Diamond"
(Annalen der Physik und Chemie, neue Folge, vol. i., p
467, 1877,; Overzier, "On the Flotation of Solid Iron in Fluid Iron " (Poggendorf's Annalen, 1870, vol. cxxix., p.
651); Akerman, "On Hardening Iron and Steel: its Causes
and Effects," Iron and Steel Institute, 1879; Tyndall, "Heat as a Mode of Motion," 1870, on Fusing Points of Substances Metals in vacuo," American Association for the Advance-
ment of Science, 1879 (Nature, Oct. 2, 1879). Proceedings of the Institution of Civil Engineers, as under: Douglas Galton, on Chilled Iron Wheels (vol. 'iii., pp. 35, 87);
Siemens and Fernie, discussion on Fox's paper on Penn-
glvania Railway (vol. xxxix., pp. 100, 110); Hackney, on he Manufacture of Steel (vol. xlii., p. 1); Siemens and
Riley, discussion on Price Williams' paper on Railways
vol. xlvi., pp. 198, 203); Euverte, on the Effects of Phos(vol. xlvi., pp. 198, 203); Euverte, on the Effects of PhosSorus and Manganese upon the Mechanical Properties of
Steel (vol. xlix., p. 360); Mannermann, Studies on the
Comentation Steel Process (vol. lvi., p. 361); Müller, on the Gementation Steel Process (vol. lvi., p. 361); Müller, on the
"Experimelosed in Iron and Steel (vol. . 11i., p. 360); Boyd,
"Expelative to Steel Boilers," Proc. Inst. Mech. E., 1878, p. 217. Mechanicc' Magazine, as under: Temper-
ng of Steel, rules by a "Clever Workman," 1855, p. 515;
R. Burn, on Tempering in Oil (1857, p. 110; M. Gaudin, on Heating Iron with Boron, Phosphate of Iron, and Peroxide pering (1867, p. 119); ditto (1870, p. 184); W. L. Austin, on
"Hardening and Tempering," 1879 (M. S.)

\section{A NEW METALlic COMPOUND.*}

By Granville Cole, Ph. D.

THE paper which I arr about to read this evening affords me the privilege of appearing for the first time before a
meeting of the members of the Society of Arts, and I hope which may attend this my first appearance as a public lecThe subject

The subject of the paper is the discovery of a metallic
compound, which I shall prove to you is new, and I shal endeavor further to set forth a few focts, attested by experithe very technical character of $m$ y subject, and the tendency

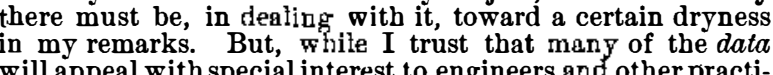
cal men, I still bope to arrest your attention by showing you to how many artistic and industrial purposes this new metal-
lic compound may be put. In the first place, it will be right

\section{I.-DISCOVERY OF THE METAL}

Nearly a year ago, Mr. J. Berger Spence discovered that
se ormed a liquid. This liquid, on cooling, became a solid homogeneous mass, possessing great tenscity and having a
peculiar dark gray -almost black - color. Nearly every metallic sulphide which is known combines, as experiments
have proved, with an excess of sulphur, and, curiously have proved, with an excess of sulphur, and, curiously ies. The combination, of which I bave specimens bere for
nspection, consists of an ore of iron pyrites, containing II.-CHEMical COMPOSITION. Examining the metal from a chemical point of view, I
may state, briefly, that it is a chemical compound belonging to that class known as thiates, or sulphur sulphides.
Dr. Hodgkinson, chemical demonstrator at the Science Schools, South Kensington, has kindly sent me the follow
ing facts. I cannot do better than quote his letter on th ibject :

It appears to be the easiest thing in the world to obtain homogeneous casting with it. Specific gravities of portion
(n) $3 \cdot 3743$ to $3 \cdot 6036$ (reduced to $0^{\circ} \mathrm{C}$.). "When finely powdered. it is acted upon slowly by con little or no action takes place. As yet I have not been able to determine the expansion equivalent accurately; it would hoidal, as might perhaps have been expected, but some "I like that of cast iron.

"I have not had time to try many 'utilization experimyking the air-tight connections beven, for instance, for means of caoutchnuc, and a water or mercury jacket, wher bout $340^{\circ}$, that it may be run into the outer tube on to th caoutchouc, which it grips on cooling, like a vice, and
makes perfectly tight. "I don't know what you may call the material, bu "ferric thiate', would not be a bad or inappropriate name." II.-PROPERTIES OF THE METAL.

I propose, this evening, to illustrate by experiments suc * A paper recently read before the Society of Arts, London. metallic compounds.

1. It has a comparatively low melting pcint, viz., 320 Fahr., or rather more than $100^{\circ}$ above the temperature of
boiling water. Here, then, we have in its favor the small amount of fuel needful to supply the $n$

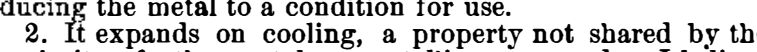
2. It expands on cooling, a property not shared by the
majority of other metals or metallic compounds. I believe I think I shall convince you that, for an operation like the joining of gas and water pipes, this expanding property is
one of great importance. It claims to resist atmospheric or climatic influences, days ago how the statues in bronze, on the Holborn viaduct, had been affected by our London fogs. And I bave ousness of the metal to such degrading influences.

4. As compared with other metals or metal ic compounds 5. A smooth surface of this metal or metallic compound, now known commercially as Spence's metal, takes a very
high polish. I will illustrate this to you by casting some of IV. - ITS USES TO ART. It may, perhaps, be interesting to my hearers to learn the
manner in which Mr. Spence first thought of utilizing this mooth surface, he had been ranning molten metal on to piece of glass, as I bave just done. But before doing so, he had chanced to touch the glass, and lad left the marks of
the pores of the skin of his fingers upon it. On removing he metal, these marks were cound to be reproduced, and so ace metal. This led $\mathrm{Mr}$. Spence to try to cast the metal i a mould; and although at present no artistic work of high enough has been done to tustify the expectation that short time, standard works of both ancient and modern colors, such as the green patina of bronze, the dark blue bue of steel, and the appearance of silver and gold, have already been obtained. Experiments are now in progress, which pound for such uses, to reproduce metallic works in thei
. riginal colors.

nove bere a casting that was made from a nickel-plat engraving; every line, however minute, has been reproduced
in Spence's metal. Experiments are now being carried on to test the adaptability of the metal for printing and stereotyping purposes, but they are not co
from giving you any facts about them. Besides this, experimental castings have been made of
various medallions and busts, notably this large bust of various medallions and busts, notably this large bust of
her Msjesty the Queen. The metal in this case has not subequently been treated in any way beyond being polished
with a cloth. The metal can be cast into almost any material used for moulds. Mr. Spence bas succeeded in obtaining casts from metal
moulds plaster moulds, and even from gelatine moulds. moulds, plaster moulds, and even from gelatine moulds. from gelatine moulds. Spence's metal, being almost a nonmould is destroyed, and if the celatine be allowed to remain on the metal till cold, it retodels itself ready for the next casting. It is, therefore, hoped that an additional process
bas been secured, by which the most undercut objects may Teproduced successfully and easily.

Therials used for artich under three heads, viz.: 1 . Cheapness. 2. Facility of work-
und a Cheapmess - As compared with lead, which is one of the cheapest of metals, it is one-third the weight; and, whereas, the average cost of lead for the last ten years has been neirly metal being three times the amount in bulk of that of a to
of lead, it is available for three times the amount of work. It may, therefore, be considered to be nearly a quarter of the price of lead, and, consequently, very considerably less Facility of Wronzing. - Its melting point being very low, it can be very easily prepared for pouring into a mould, and
its property of expanding, when cooling, causes it to take its property of expanding, when cooling, causes it to take
such a perfect impression that the cast requires very little cover a considerable surface of work withoutd, which can one has to make in plaster piece moulding, lhe metal cast
obtained from such a mould would require no chasing what Resistance to the Atmosphere. - With regard to its resistance to climatic influences, experiments have been conducted in
this direction with complete success. A polished surface of
the metal has been exposed for six months in all weathers without showing the least change.
Mr. Wood, the secretary of this society, has had a me. dallion, which I sent him a month ago, exposed to all the
recent fogs and frosts, on the outside of this building. You can judge and see for yourselves bow well it has stood this Not to confine myself to this test alone, I have here has been left for the same period in aqua-regia, one of the strongest acids known. You see how little effect the acid has had on the surface of the metal. I believe that no work
of art in any other substance would bear this test without suffering. I will bere endeavor to show you the effect the if Spence's metal marble or bronze. I venture to think that certainly to be able to resist the climate of London for a much longer period. I, therefore, beg to submit that this
metal, if skilled labor is brought to bear on it, ought to be
of a great value for decorative purposes, both internal and external.
v.-INDUSTRIal uses.

I will endeavor now to point out to you the uses to which
his metal may be applied for industrial purposes. And I propose to divide these purposes under three heads : 1 . Gas propose to divide 2 . Chemical works. 3. Miscellaneous.
and water works. I will simply relate, as best I can, those experiments which
have been tried at the Bouth Metropolitan Grs-works. EX. 
